\title{
Efficacy of anakinra in gouty arthritis: a retrospective study of 40 cases
}

\author{
Sébastien Ottaviani ${ }^{1}$, Anna Moltó ${ }^{2}$, Hang-Korng Ea², Séverine Neveu ${ }^{3}$, Ghislaine Gill', Lauren Brunier ${ }^{1}$, \\ Elisabeth Palazzo ${ }^{1}$, Olivier Meyer ${ }^{1}$, Pascal Richette ${ }^{2}$, Thomas Bardin² ${ }^{2}$ Yannick Allanore ${ }^{4}$, Frédéric Lioté ${ }^{2}$ \\ Maxime Dougados ${ }^{3}$ and Philippe Dieudé ${ }^{*}$
}

\begin{abstract}
Introduction: Gout is a common arthritis that occurs particularly in patients who frequently have associated comorbidities that limit the use of conventional therapies. The main mechanism of crystal-induced inflammation is interleukin-1 production by activation of the inflammasome. We aimed to evaluate the efficacy and tolerance of anakinra in gouty patients.

Methods: We conducted a multicenter retrospective review of patients receiving anakinra for gouty arthritis. We reviewed the response to treatment, adverse events and relapses.

Results: We examined data for 40 gouty patients (32 men; mean age $60.0 \pm 13.9$ years) receiving anakinra. Mean disease duration was $8.7 \pm 8.7$ years. All patients showed contraindications to and/or failure of at least two conventional therapies. Most (36; 90\%) demonstrated good response to anakinra. Median pain on a 100-mm visual analog scale was rapidly decreased (73.5 (70.0 to 80.0) to 25.0 (20.0 to 32.5$) \mathrm{mm}, P<0.0001$ ), as was median Creactive protein (CRP) level (130.5 (55.8 to 238.8) to 16.0 (5.0 to 29.5$) \mathrm{mg} / \mathrm{l}, P<0.0001$ ). After a median follow-up of 7.0 (2.0 to 13.0) months, relapse occurred in 13 patients after a median delay of 15.0 (10.0 to 70.0) days. Seven infectious events, mainly with long-term use of anakinra, were noted.
\end{abstract}

Conclusions: Anakinra may be efficient in gouty arthritis, is relatively well tolerated with short-term use, and could be a relevant option in managing gouty arthritis when conventional therapies are ineffective or contraindicated. Its long-term use could be limited by infectious complications.

Keywords: gout, IL-1, anakinra, arthritis

\section{Introduction}

Gout is a common arthritis caused by deposition of monosodium urate (MSU) crystals within and around joints secondary to chronic hyperuricemia. It affects $1 \%$ to $2 \%$ of adults in developed countries and may be increasing in prevalence [1]. Acute gouty arthritis may be associated with high inflammatory clinical and biological symptoms. Thus, one of the goals of management is rapid relief of inflammation [2,3].

Acute gouty attacks are usually treated with nonsteroidal anti-inflammatory drugs (NSAIDs), colchicine and

\footnotetext{
* Correspondence: philippe.dieude@bch.aphp.fr

${ }^{1}$ Université Paris Diderot, Sorbonne Paris Cité, UFR de Médecine, F-75205 Paris, France; AP-HP, Service de Rhumatologie, Hôpital Bichat, 75018 Paris, France

Full list of author information is available at the end of the article
}

corticosteroids [3]. Gouty patients often have concomitant renal, cardiovascular and gastrointestinal diseases as well as diabetes mellitus [4]. These comorbidities and associated treatments can lead to increased frequency of side effects or contraindications to conventional therapies for gouty arthritis [4]. We have abundant evidence of side effects from the use of colchicine (for example, for diarrhea) [5] and NSAIDs (for example, for gastrointestinal bleeding, cardiovascular events including myocardial infarction, renal impairment) [6,7], so care must be taken when prescribing such drugs. Thus, alternative therapies are needed for these 'difficult-to-treat' cases.

The main mechanism of crystal-induced inflammation is interleukin $1 \beta$ (IL-1 $\beta$ ) production by activation of the NLRP3 inflammasome [8], which strengthens the relevance of targeting IL- $1 \beta$ in patients with crystal-induced 
arthritis. Anti-IL-1 agents, such as anakinra, have been evaluated in gouty arthritis, for treating acute attacks or for preventing gouty attacks while initiating urate-lowering therapy [9-14]. To date, only two small open studies have evaluated the efficacy of anakinra in acute gouty arthritis $[13,14]$ although anakinra has been labeled for rheumatoid arthritis treatment for more than 10 years. Other IL-1 inhibitors, canakinumab and rilonacept, appear to be effective in reducing pain and signs of inflammation in randomized controlled trials, which validate IL- 1 as playing a pivotal role in gout inflammation $[9,10,12,15]$.

Here, we aimed to evaluate the efficacy and safety of anakinra in patients with acute and chronic gouty arthritis but with contraindications to or failure of conventional therapies.

\section{Methods \\ Patients}

This was a multicenter retrospective review of charts for patients who received anakinra for gouty arthritis. Patients were identified by treating rheumatologists and by searching available electronic medical records with the keyword 'anakinra' or 'Kineret ${ }^{\circledR}$ '. Patients receiving anakinra who had concomitant connective tissue diseases were not included. Inclusion criteria were diagnosis of gouty arthritis defined as recommended by the identification of MSU crystals in synovial fluid [16] and at least one documented visit after the acute gouty arthritis requiring anakinra. The study was approved by the local institutional review board of Paris North Hospitals (No. 12-081) and all patients provided informed written consent to their physician to receive anakinra.

\section{Evaluation}

We retrospectively assessed response to anakinra at baseline and at the first documented visit following the acute gouty arthritis according to the following items: swollen joint count (SJC) and tender joint count (TJC), patient evaluation of pain by a visual analog scale (VAS pain, 0 to $100 \mathrm{~mm}$ ) and C-reactive protein (CRP) levels $(\mathrm{mg} / \mathrm{L})$. We collected data on demographics (age, gender), clinical variables (tophus, localization of arthritis, comorbid conditions, and disease and flare duration), radiologic features of gouty arthropathy and biological variables (serum uric acid levels (SUA), CRP and creatinine). The outcome of anakinra treatment was classified as good, partial, or no response. A good response was arbitrarily defined as an improvement $>50 \%$ in VAS pain or CRP level and/or documentation in the chart of the word 'good' response after anakinra treatment. A partial response was defined as a report of improvement in joint symptoms but not a 'good' response (20\% to $50 \%$ improvement). No response was defined as the absence of symptom relief ( $<20 \%$ improvement).
Adverse events were defined as diarrhea, myopathy and skin reactions with colchicine treatment; gastrointestinal bleeding, cardiovascular events, renal impairment and skin reactions with NSAIDs; hyperglycemia, hypertension and cardiovascular events with steroids; and local skin reaction, infection and neutropenia with anakinra.

Contraindications to conventional therapies and comorbidities were as described [4], except for osteoporosis and hyperlipidemia, which we did not consider a comorbidity limiting prescription of conventional therapies.

\section{Statistical analysis}

Data are reported as mean \pm SD or median (interquartile range (IQR)) or number (\%). Non-parametric or Fisher's exact test was used to compare quantitative or categorical data, respectively. A two-tailed $P<0.05$ was considered statistically significant.

\section{Results}

\section{Baseline characteristics}

We investigated data for 40 patients ( 32 men) who received anakinra for gouty arthritis. Their baseline characteristics are shown in Table 1. In all, 79\% and 92\% of patients showed clinical tophi and gouty arthropathy, respectively.

At baseline, the median (IQR) pain level was 73.5 (70.0 to 80.0 ) $\mathrm{mm}$. The median TJC and SJC was 5.0 (3.5 to 8.0) and 4.0 (3.0 to 5.5), respectively. The median CRP level was 130.5 (55.8 to 238.8$) \mathrm{mg} / \mathrm{L}$. The mean SUA was $534 \pm$ $172 \mu \mathrm{M}$. In all, 17 (43\%) patients had received uratelowering therapy (allopurinol $(n=11)$, febuxostat $(n=6)$, benzbromarone $(n=1))$. Diuretic drugs were prescribed for 14 patients (hydrochlorothiazides $(n=3)$, loop diuretics $(n=11))$. All patients had a contraindication to or past history of adverse events with conventional treatments for acute gouty arthritis (Table 1).

The number of patients with gouty arthritis that was acute $(<6$ weeks), subacute ( 6 to 12 weeks) and chronic (>12 weeks) was 34, 2 and 4, respectively.

Among the 40 patients, 23 received anakinra following the protocol used by So et al.[14]: $100 \mathrm{mg}$ daily for three days subcutaneously. Seven patients received anakinra for $<15$ days $(100 \mathrm{mg} /$ day: $n=6,100 \mathrm{mg} / 2$ days: $n=1)$. The 10 remaining patients received anakinra for the long term ( $>15$ days), followed by a spacing of the dose regimen (median total duration: 5.0 (2.3 to 11.8 ) months).

\section{Anakinra response for gouty arthritis Whole population}

Of the 40 patients, good, partial and non-response to anakinra were noted in $36(90 \%), 2(5 \%)$ and 2 patients (5\%), respectively. Pain score decreased from 73.5 (70.0 to 80.0) to 25.0 (20.0 to 32.5$) \mathrm{mm}, P<0.0001)$, as did CRP 
Table 1 Baseline characteristics of patients receiving anakinra for gouty arthritis.

\begin{tabular}{|c|c|}
\hline Baseline characteristics & Clinical characteristics of gouty patients \\
\hline Number of patients & 40 \\
\hline Number of men (\%) & $32(80 \%)$ \\
\hline Comorbid conditions (number; \%) & $\begin{array}{l}\text { HT (27; 68\%), CKD 3-5 (22; 55\%), CAD (17; 43\%), Al (13; 33\%), DM (9; 23\%), GU (6; 15\%), } \\
\text { transplant (2 (kidney, heart); 5\%), asthma (1; 3\%), }\end{array}$ \\
\hline Associated therapies (number; \%) & LDA (8; 20\%), oral anticoagulant $(3 ; 8 \%)$ \\
\hline Age, year, mean $\pm S D$ & $60.0 \pm 13.9$ \\
\hline Disease duration, year, mean \pm SD & $8.7 \pm 8.7$ \\
\hline \multicolumn{2}{|l|}{ Flare duration, number patients (days, mean \pm SD) } \\
\hline Acute ( $<6$ weeks) & $34(9.4 \pm 8.1)$ \\
\hline Subacute (6 to 12 weeks) & $2(60.0 \pm 1.4)$ \\
\hline Chronic (>12 weeks) & $4(130 \pm 45.8)$ \\
\hline Localization of arthritis, (number; \%) & $\begin{array}{l}\text { Knees }(30 ; 75 \%) \text {, wrists }(22 ; 55 \%) \text {, ankles }(24 ; 60 \%) \text {, MTP1s (20; } 50 \%) \text {, MCPs }(12 ; 30 \%) \text {, elbows } \\
(12 ; 30 \%) \text {, tarsae }(6 ; 15 \%) \text {, shoulders }(2 ; 5 \%)\end{array}$ \\
\hline \multicolumn{2}{|l|}{ Reason for anakinra use } \\
\hline $\begin{array}{l}\text { Non-response to conventional therapies, } \\
\text { (number; \%) }\end{array}$ & Colchicine $(24 ; 60 \%)$, NSAIDs $(11 ; 27.5 \%)$, steroids (7; $17.5 \%)$ \\
\hline $\begin{array}{l}\text { Adverse events or contraindication to } \\
\text { conventional therapies, (number; \%) }\end{array}$ & Colchicine $(16 ; 40 \%)$, NSAIDs $(29 ; 72.5 \%)$, steroids (9; 22.5\%) \\
\hline
\end{tabular}

Al, alcohol intake; CAD, coronary heart disease; CKD, chronic kidney disease; DM, diabetes mellitus; GU, gastric ulcer; HT, hypertension, LDA, low-dose aspirin; MCPs, metacarpophalangeal joints; MTPs, metatarsophalangeal joints; NSAIDs, non-steroidal anti-inflammatory drugs.

level (130.5 (55.8 to 238.8 ) to 16.0 (5.0 to 29.5$) \mathrm{mg} / \mathrm{L}$, $P<0.0001$ ) (Figure 1). In all, 30 patients received treatment to prevent relapse (Table 2). After a median follow-up of 7.0 (2.0 to 13.0 ) months, relapse occurred in 13 (32.5\%) patients with a median delay of 15.0 (10.0 to 70.0) days. Relapse occurred particularly in patients not receiving therapy to prevent acute flare $(7 / 10$ versus $6 / 30, P=$ $0.006)$. No relapse occurred with long-term use of anakinra (>15 days).

\section{Anakinra response according to the dose regimen}

A total of 23 patients received anakinra, $100 \mathrm{mg} /$ day, for up to three days, with good response in 20 (87\%); 17 (74\%) showed relapse prevention after resolution of the flare. After a median follow-up of 6.0 (1.5 to 14.0) months, relapse occurred in six (26\%) patients at a median delay of 15.0 (6.0 to 26.3 ) days.

In all, 17 patients received anakinra for more than three days, with good response in 16 (94\%); 13 (76\%) showed
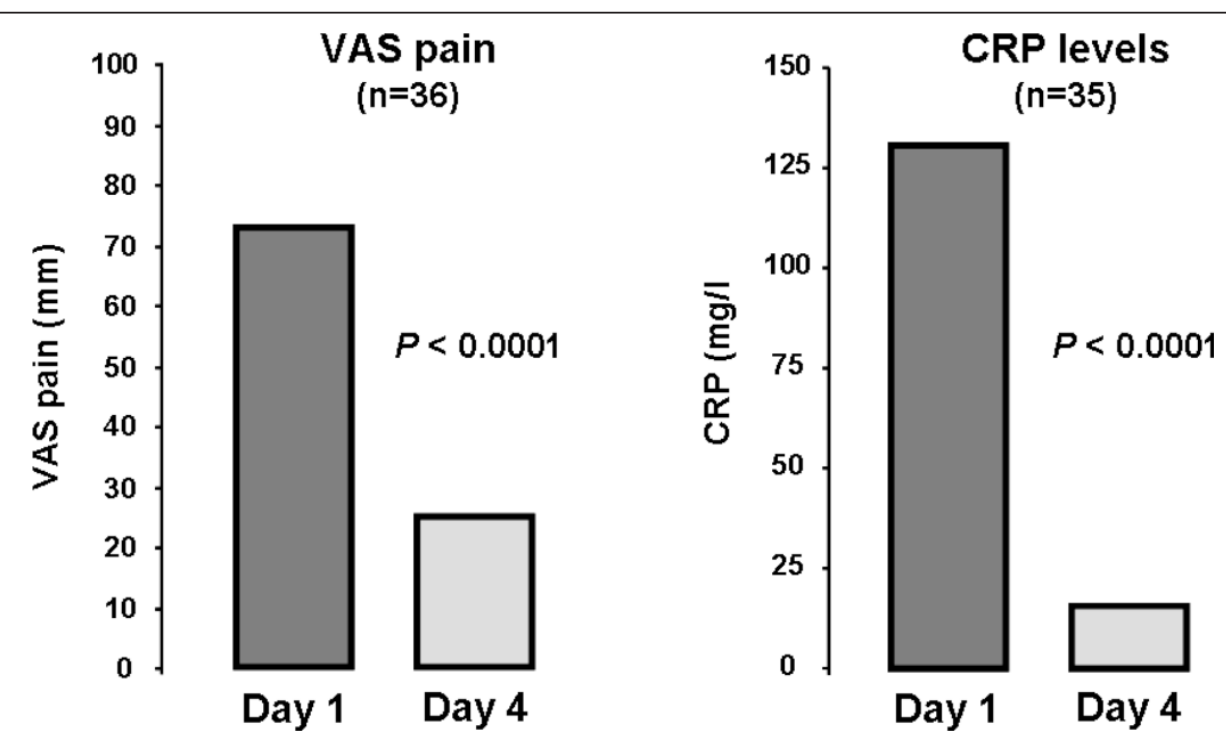

Figure 1 Pain on a visual analog scale (VAS) and C-reactive protein level (CRP) on days 1 and 4 of anakinra treatment for gouty arthritis. VAS, visual analog scale (mm); CRP, C-reactive protein (mg/l). 
Table 2 Response and follow-up of gouty arthritis patients receiving anakinra.

\begin{tabular}{|c|c|c|}
\hline Follow-up characteristics & $\begin{array}{c}\text { Anakinra for } \leq 3 \text { days } \\
\text { Number }=23\end{array}$ & $\begin{array}{c}\text { Anakinra for }>3 \text { days } \\
\text { Number }=17\end{array}$ \\
\hline \multicolumn{3}{|l|}{ Response to anakinra, number (\%) } \\
\hline Good & $20(87 \%)$ & $16(94 \%)$ \\
\hline Partial & $2(9 \%)$ & $0(0 \%)$ \\
\hline No response & $1(4 \%)$ & $1(6 \%)$ \\
\hline Follow-up duration, months, median (IQR) & $6.0(1.5$ to 14.0$)$ & $8.0(3.0$ to 13.0$)$ \\
\hline \multicolumn{3}{|l|}{ Prevention of relapse, number (\%) } \\
\hline Total & $17(74 \%)^{\mathrm{a}}$ & $13(76 \%)$ \\
\hline Low-dose colchicine & $16(89 \%)$ & $7(54 \%)$ \\
\hline NSAIDs & $3(17 \%)$ & $1(8 \%)$ \\
\hline Steroids & $1(6 \%)$ & $2(15 \%)$ \\
\hline Anakinra & $1(6 \%)$ & $9(69 \%)$ \\
\hline Relapse, number (\%) & $6(26 \%)$ & $7(41 \%)$ \\
\hline Delay to relapse, days, median (IQR) & $15.0(6.0$ to 26.3$)$ & $60.0(12.5$ to 125.0$)$ \\
\hline Skin reaction & None & None \\
\hline $\begin{array}{l}\text { Infectious events under anakinra therapy } \\
\text { (delay after starting anakinra) }\end{array}$ & H1N1 infection (1 day) & $\begin{array}{l}\text { Staphylococcus aureus tophus ( } 1 \text { year) } \\
\text { S. aureus tophus ( } 4 \text { years) } \\
\text { S. aureus lung abcess ( } 1 \text { month) } \\
\text { Erysipela of the leg ( } 2 \text { months) } \\
\text { Streptococcus B urinary tract infection ( } 1 \text { month) } \\
\text { S. aureus knee arthritis ( } 1 \text { year) }\end{array}$ \\
\hline
\end{tabular}

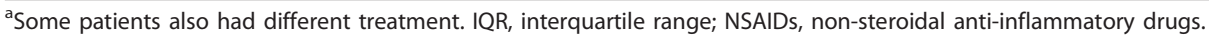

relapse prevention after flare resolution. After a median follow-up of 8.0 (3.0 to 13.0) months, relapse occurred in seven $(41 \%)$ patients at a median delay of $60.0(12.5$ to 125.0) days.

\section{Tolerance}

No patient reported anakinra-related skin hypersensitivity. A total of seven infectious complications, mainly staphylococcal infections, were reported in six patients (Table 2). One H1N1 viral infection occurred one day after anakinra was started (previously reported in [17]). All other infectious complications occurred in patients with long-term use of anakinra and were successfully treated with antibiotics. Of the six patients, five restarted anakinra after the resolution of infection. No patient has shown tuberculosis or pneumococcal infection.

\section{Discussion}

Recently, the emerging role of IL- $1 \beta$ in the pathogenesis of inflammation in crystal-induced arthritis $[8,18,19]$ led to considering anti-IL-1 therapies as a relevant alternative to conventional therapies for gouty arthritis. Here, we report on our experience with anakinra therapy, a recombinant receptor antagonist against IL-R blocking both IL-1 $\beta$ and $\beta$, for gouty arthritis in a large series of patients. Our results are in good agreement with those of the first openlabel trial of anakinra showing improved patient-reported symptoms by at least $50 \%$ of all 10 patients enrolled [14]. Chen et al. suggested an efficiency in 6 of 10 patients with good response [13]. Similar to So et al., we observed a rapid decrease of both VAS pain and CRP levels. Recently, randomized controlled trials found that two anti-IL-1 $\beta$ biologic agents (rilonacept and canakinumab) prevented gouty arthritis during the initiation of urate-lowering therapy with allopurinol $[10,11]$, but only canakinumab demonstrated efficacy for acute gouty arthritis $[9,12]$. In these cases, rilonacept failed to induce a rapid relief of symptoms [20] but could decrease pain in chronic gouty arthritis [15]. These data strengthen the argument to target IL-1 blockade for acute gouty arthritis. Of interest, canakinumab recently obtained European authorization [21].

In our study, relapse occurred frequently among patients not receiving therapy to prevent acute flare, and conversely, no patient with long-term use of anakinra experienced relapse. The daily subcutaneous injection could limit the use of the drug in preventing flare, although skin tolerance was excellent in our study. The short-term regimen was well tolerated: only one viral infection was observed. This short-term good tolerance agrees with previous studies of anakinra for gouty arthritis [13,14] and pseudogout [22,23]. However, long-term use was poorly tolerated, with six infectious events, notably one septic arthritis and one patient with pulmonary abscesses. These data suggest a risk of infection with prolonged administration. To date, the role IL-1 antagonists could play in clinical practice is unclear. Nonetheless, their cost (38€ per injection in France, 2013) may not be excessive in managing acute attacks, particularly in patients with contraindications to, or who cannot tolerate, conventional therapies. Recently, American College of Rheumatology recommendations 
allow for use of anti-IL1 agents when conventional therapies have failed or are contraindicated [2]. Of note, anakinra, with the shortest half-life of the IL-1 blockers, could be a relevant option to manage acute gouty arthritis.

Our study had some limitations. First, data were retrospectively collected, with varied use of anakinra, and we had no control group. However, this real-life observational study is the largest reported series for this treatment. Randomized controlled studies are necessary to clarify the place of anakinra in the management of gouty arthritis flare.

\section{Conclusions}

Our results provide evidence that anakinra is effective, relatively well tolerated with short-term use, and could be a good alternative for treating gouty arthritis in patients for whom conventional therapies are ineffective or contraindicated. Although these findings are promising, this was a retrospective study, and future randomized controlled trials are required definitely to determine the place of anakinra in managing gouty arthritis.

\section{Abbreviations}

CRP: C-reactive protein; IL-1: interleukin-1; IQR: interquartile range; MSU: monosodium urate; NSAIDs: nonsteroidal anti-inflammatory drugs; SD: standard deviation; SJC: swollen joint count; SUA: serum uric acid; TJC: tender joint count; VAS: visual analog scale.

\section{Competing interests}

Frédéric Lioté received unrestricted grants from SOBI France and Novartis since 2010 for helping set up an annual European Workshop on crystalinduced inflammation and human diseases. The other authors declare they have no competing interests.

\section{Authors' contribution}

SO and PD conceived of the study, made substantial contributions to the acquisition of data, participated in its design, and wrote the manuscript. AM, HKE, SN, GG, LB, EP, PR, TB, YA, FL, MD and OM made substantial contributions to the acquisition of data and helped to draft the manuscript All authors read and approved the final manuscript.

\section{Acknowledgements}

We thank Laura Smales for copyediting.

\begin{abstract}
Authors' details
'Université Paris Diderot, Sorbonne Paris Cité, UFR de Médecine, F-75205 Paris, France; AP-HP, Service de Rhumatologie, Hôpital Bichat, 75018 Paris, France. ${ }^{2}$ Université Paris Diderot, Sorbonne Paris Cité, UFR de Médecine, F75205 Paris, France; AP-HP, Service de Rhumatologie, Pôle appareil Locomoteur, Hôpital Lariboisière, F-75475 Paris, France. ${ }^{3}$ Université René Descartes, Service de Rhumatologie B, Hôpital Cochin, APHP, Paris, France. ${ }^{4}$ Université René Descartes, Service de Rhumatologie A, Hôpital Cochin, APHP, Paris, France.
\end{abstract}

Received: 19 March 2013 Revised: 24 June 2013

Accepted: 17 September 2013 Published: 17 September 2013

\section{References}

1. Richette P, Bardin T: Gout. Lancet 2009, 375:318-328

2. Khanna D, Khanna PP, Fitzgerald JD, Singh MK, Bae S, Neogi T, Pillinger MH, Merill J, Lee S, Prakash S, Kaldas M, Gogia M, Perez-Ruiz F, Taylor W, Liote F, Choi H, Singh JA, Dalbeth N, Kaplan S, Niyyar V, Jones D, Yarows SA, Roessler B, Kerr G, King C, Levy G, Furst DE, Edwards NL, Mandell B,
Schumacher HR, et al: 2012 American College of Rheumatology guidelines for management of gout. Part 2: therapy and antiinflammatory prophylaxis of acute gouty arthritis. Arthritis Care Res (Hoboken) 2012, 64:1447-1461

3. Zhang W, Doherty M, Bardin T, Pascual E, Barskova V, Conaghan P, Gerster J, Jacobs J, Leeb B, Liote F, McCarthy G, Netter P, Nuki G, Perez-Ruiz F, Pignone A, Pimentao J, Punzi L, Roddy E, Uhlig T, Zimmermann-Gorska I: EULAR evidence based recommendations for gout. Part II: management. Report of a task force of the EULAR Standing Committee for International Clinical Studies Including Therapeutics (ESCISIT). Ann Rheum Dis 2006, 65:1312-1324.

4. Keenan RT, O'Brien WR, Lee KH, Crittenden DB, Fisher MC, Goldfarb DS, Krasnokutsky S, Oh C, Pillinger MH: Prevalence of contraindications and prescription of pharmacologic therapies for gout. Am J Med 2011, 124:155-163.

5. Terkeltaub RA: Colchicine update: 2008. Semin Arthritis Rheum 2009, 38:411-419.

6. Park SC, Chun HJ, Kang CD, Sul D: Prevention and management of nonsteroidal anti-inflammatory drugs-induced small intestinal injury. World J Gastroenterol 2011, 17:4647-4653.

7. Brater DC: Anti-inflammatory agents and renal function. Semin Arthritis Rheum 2002, 32:33-42.

8. Martinon F, Petrilli V, Mayor A, Tardivel A, Tschopp J: Gout-associated uric acid crystals activate the NALP3 inflammasome. Nature 2006, 440:237-241.

9. So A, De Meulemeester M, Pikhlak A, Yucel AE, Richard D, Murphy V, Arulmani U, Sallstig P, Schlesinger N: Canakinumab for the treatment of acute flares in difficult-to-treat gouty arthritis: results of a multicenter, phase II, dose-ranging study. Arthritis Rheum 2010, 62:3064-3076.

10. Schumacher HR Jr, Evans RR, Saag KG, Clower J, Jennings W, Weinstein SP, Yancopoulos GD, Wang J, Terkeltaub R: Rilonacept (interleukin-1 trap) for prevention of gout flares during initiation of uric acid-lowering therapy: results from a phase III randomized, double-blind, placebo-controlled, confirmatory efficacy study. Arthritis Care Res (Hoboken) 2012, 64:1462-1470.

11. Schlesinger N, Mysler E, Lin HY, De Meulemeester M, Rovensky J, Arulmani U, Balfour A, Krammer G, Sallstig P, So A: Canakinumab reduces the risk of acute gouty arthritis flares during initiation of allopurinol treatment: results of a double-blind, randomised study. Ann Rheum Dis 2011, 70:1264-1271.

12. Schlesinger $N$, Alten RE, Bardin T, Schumacher HR, Bloch M, Gimona A, Krammer G, Murphy V, Richard D, So AK: Canakinumab for acute gouty arthritis in patients with limited treatment options: results from two randomised, multicentre, active-controlled, double-blind trials and their initial extensions. Ann Rheum Dis 2012, 71:1839-1848.

13. Chen K, Fields T, Mancuso CA, Bass AR, Vasanth L: Anakinra's efficacy is variable in refractory gout: report of ten cases. Semin Arthritis Rheum 2010, 40:210-214.

14. So A, De Smedt T, Revaz S, Tschopp J: A pilot study of IL-1 inhibition by anakinra in acute gout. Arthritis Res Ther 2007, 9:R28.

15. Terkeltaub R, Sundy JS, Schumacher HR, Murphy F, Bookbinder S, Biedermann S, Wu R, Mellis S, Radin A: The interleukin 1 inhibitor rilonacept in treatment of chronic gouty arthritis: results of a placebo-controlled, monosequence crossover, non-randomised, single-blind pilot study. Ann Rheum Dis 2009, 68:1613-1617.

16. Zhang W, Doherty M, Pascual E, Bardin T, Barskova V, Conaghan P, Gerster J, Jacobs J, Leeb B, Liote F, McCarthy G, Netter P, Nuki G, Perez-Ruiz F, Pignone A, Pimentao J, Punzi L, Roddy E, Uhlig T, Zimmermann-Gorska I: EULAR evidence based recommendations for gout. Part I: diagnosis. Report of a task force of the Standing Committee for International Clinical Studies Including Therapeutics (ESCISIT). Ann Rheum Dis 2006, 65:1301-1311.

17. Nocturne G, Ora J, Ea HK, Liote F: Influenza A H1N1 and anakinra exposure in a patient with gout. Joint Bone Spine 2010, 77:369-370.

18. Gross O, Yazdi AS, Thomas CJ, Masin M, Heinz LX, Guarda G, Quadroni M, Drexler SK, Tschopp J: Inflammasome activators induce interleukin-1alpha secretion via distinct pathways with differential requirement for the protease function of caspase-1. Immunity 2012, 36:388-400.

19. Church LD, Cook GP, McDermott MF: Primer: inflammasomes and interleukin 1beta in inflammatory disorders. Nat Clin Pract Rheumatol 2008, 4:34-42. 
20. Terkeltaub RA, Schumacher HR, Carter JD, Baraf HS, Evans RR, Wang J, King-Davis S, Weinstein SP: Rilonacept in the treatment of acute gouty arthritis: a randomized, controlled clinical trial using indomethacin as the active comparator. Arthritis Res Ther 2013, 15:R25.

21. Euopean Medicines Agency: Ilaris. 2013 [http://www.ema.europa.eu/docs/ fr_FR/document_library/EPAR_-_Summary_for_the_public/human/001109/ WC500031677.pdf].

22. Molto A, Ea HK, Richette P, Bardin T, Liote F: Efficacy of anakinra for refractory acute calcium pyrophosphate crystal arthritis. Joint Bone Spine 2012, 79:621-623.

23. Ottaviani $S$, Brunier L, Sibilia J, Maurier F, Ardizzone M, Wendling D, Gill G, Palazzo E, Meyer O, Dieude P: Efficacy of anakinra in calcium pyrophosphate crystal-induced arthritis: a report of 16 cases and review of the literature. Joint Bone Spine 2013, 80:178-182.

doi:10.1186/ar4303

Cite this article as: Ottaviani et al.: Efficacy of anakinra in gouty arthritis: a retrospective study of 40 cases. Arthritis Research \& Therapy 201315

R123.

\section{Submit your next manuscript to BioMed Central} and take full advantage of:

- Convenient online submission

- Thorough peer review

- No space constraints or color figure charges

- Immediate publication on acceptance

- Inclusion in PubMed, CAS, Scopus and Google Scholar

- Research which is freely available for redistribution

Submit your manuscript at www.biomedcentral.com/submit 